be overcome. One early chapter reviews a survey of specialist registrars' attitudes to research opportunities during their training, and the obstacles they face. Lack of time, appropriate support and their need for supervision are already widely recognised, but here the authors reveal less well appreciated and more ominous sounding syndromes, including "the canteen culture" of the "anti-research milieu", profound attacks of procrastination and acute unpredictable episodes of deep-seated vacillation. A later chapter, entitled 'Maintaining momentum', revisits each of these potential obstacles one by one, inviting the readers to identify those barriers most relevant to their own progress, helping them to devise specific plans to overcome them. Presentation is another strong point of this publication, with emphasis placed on the use of summary boxes in the text to direct the reader's attention to the salient issues raised in each of the chapters.

In taking this practical, problemfocused approach less space is devoted to more technical questions, such as study design or sample selection. The coverage of such issues relevant to quantitative studies is therefore not exhaustive, while those for qualitative designs is almost non-existent, and is mainly limited to highlighting the various differences between these two approaches. For instance, there are three chapters dealing with aspects of the analysis of quantitative data, but virtually no mention is made of the range of methods appropriate to the analysis of qualitative material. This seems to be a lost opportunity when a pluralist approach combining both methods is now promoted by many investigators, as well as those who commission their work. If support for research generally is hard to come by, that for qualitative approaches in particular is even thinner on the ground. A similarly practical approach in this area would have been a bonus.

This is a useful book, and contains much wisdom for anyone interested in the 'how to do it' of research work. The text seems to roll along with a momentum of its own, and is pervaded with a sense of the editors' enthusiasm. It is refreshingly down to earth and accessible, and the covers of many of its copies will quickly become dog-eared and tatty around the edges because its owners have so often had reason to dip into it and draw on the useful lessons learnt, and shared here, by others.

Sarah Marriott, Consultant Psychiatrist, Paterson Centre for Mental Health, 20 South Wharf Road, London W2 1PD

\section{The Marriage of Heaven and Hell}

By Peter Dally. London: Robson. 1999. 225 pp. £16.95. ISBN 1-86105-219-7

If you are from the upper social classes and becoming manic, your illness is manifest in slightly more flamboyant ways; in 1908 Virginia Woolf and friends took part in the now famous Dreadnought Hoax. A telegram was sent to HMS Dreadnought, the flagship of the British home fleet then anchored at Weymouth, advising the Admiral of a visit by the Emperor of Abyssinia and four of his entourage. The group (Woolf et al) all disguised by dark greasepaint and wearing flowing robes, were met by a guard of honour at the station and escorted round the ship by the captain. Woolf's brother played the interpreter and used what one sailor called a 'rum lingo'. Virginia remained silent, which is perhaps why they escaped detection. They got back safely and all would have been well, had not one of the party informed the press, whereupon a storm broke over their heads.

This anecdote comes from Peter Dally's biography of Virginia Woolf, with particular reference to her manic-depressive illness and the desperate attempts by her husband, Leonard, to cope with it. A retired consultant psychiatrist from the Westminster Hospital, Dally has painstakingly researched the inner dynamics of the dazzling Bloomsbury group. The gripping story that emerges is that some of the 20th century's brightest minds seemed curiously incapable of applying their intellects to the basic challenges of the emotional difficulties in their own lives.

Earlier in her life, Lytton Strachey, widely known to be a confirmed homosexual, proposed to Virginia and she accepted, to his shock and dismay, but they both managed to extricate themselves from the quagmire.

Leonard and Virginia's own married sex life seems to have been deeply unsatisfactory from an early stage, yet they appeared to have done little to use their vast educational resources to inform themselves about possible solutions. Despite Leonard taking over the publishing of the International PsychoAnalytical Library, he made almost no attempts to obtain any kind of ongoing therapeutic help for Virginia's manic depression. She read Freud 'compulsively' for a while, yet also seemed unable to attempt any psychological understanding of her moods. No doctor specialising in neurology or psychiatry was ever engaged for help by the Woolfs for any prolonged period.

Dally prefers dispassionate reporting of the facts rather than a polemic, but what emerges is a group of gifted individuals reduced to rather immature avoidances whenever in danger of confronting their own difficulties. There are some interesting clues here for the clinical psychiatrist of why sometimes the most intellectual patients are oddly the most difficult to treat.

Indeed, this eventually proved Virginia's undoing as Leonard took her to see a kind of family doctor inexperienced in mental illness, living miles away, for an inadequate consultation the day before her suicide. The ultimate tragedy of untreated manic depression is poignantly apparent in her suicide note - the deep loss to all of us when creativity and genius cannot be protected from the ravages of mental illness, or perhaps darkly inevitable insight. Her final lines ever include "... I am certain I am going mad again ... I am always hearing voices, and I know I shan't get over it now."

Raj Persaud, Consultant Psychiatrist, Maudsley Hospital, De Crespigny Park, Denmark Hill, London SE5 8AF

\title{
miscellany
}

\section{Treatment decisions in young people -- new information sheets by FOCUS}

Involving children and adolescents in decisions about their medical treatment has been an area of considerable debate and contention for some time. This issue has been front-page news, especially when controversial court decisions are made to overrule children's and/or parents' decisions about the medical treatment they wish to receive or decline. This is, however, an everyday issue for practitioners who care for children. For this reason, FOCUS, the child and adolescent mental health project at the Royal College of Psychiatrists' Research Unit has produced a set of three information sheets that give an overview of some of the key issues in this complex area.

Sheet number 1: The Legal Framework covers issues such as consent, refusal and competence (to decide) in relation to Acts 
of Parliament and court rulings that have set legal precedents.

Sheet number 2: Practice Guidelines gives guidance and advice to clinicians working with children where issues of consent from the child, parent(s) or guardian are an essential part of the treatment plan. Case studies are used to illustrate the complexity of these situations, for example, the treatment of a child with anorexia nervosa who is refusing to eat.

Sheet number 3: Frequently Asked Questions and References lists common questions about children and their involvement in treatment decisions in terms of consent, refusal and competence. Full references are listed together with a 'further reading' section.

The sheets are aimed at all practitioners who look after children as well as parents and key interest and welfare groups. For further information, please contact Carol Joughin, FOCUS Project Manager, College Research Unit (telephone: 02072352351 ext 256).

\section{forthcoming events}

Clinical Excellence 2000 - promoting quality in mental health and learning disabilities is the title of the Royal College of Psychiatrists Research Unit's fifth multi-professional conference focusing on quality and effectiveness issues in mental health services. The event's themes are more important than ever, as the introduction of clinical governance means that quality and effectiveness are now central to the NHS agenda. This conference focuses on achieving excellence in mental health and learning disability services from a practical perspective. Initial presentations will set the scene for creating quality in mental health services in the 'New NHS' and parallel sessions will focus on current developments in mental health services to promote excellence, changing the culture of mental health services to facilitate and nurture quality improvements and real examples of projects that have made a difference. The event aims to provide an opportunity for people working in mental health and learning disability services to share best practice and innovative ideas at both strategic and practice levels and uses a parallel session format to help delegates select a range of sessions that they will find most useful. Further information: Sam Coombs, Communications Officer, College Research Unit (Telephone: 020 72352351 ext 234).

Professor R. N. Mohan, Consultant in Old Age Psychiatry and Clinical Tutor for the Northern Birmingham Mental Health NHS Trust is the organiser of three twoday courses. Mental health law update for specialist registrars, being held on 7-8 March 2000 and Mental health law update for consultant psychiatrists, being held on 6-7 April 2000, will focus on key issues related to the Mental Health Act and Mental Health Law. Management course for specialist registrars in psychiatry, which will take place on 4-5 May 2000, will cover NHS structures and functions, terms and conditions of service, time management and negotiating skills. Further information about all the courses, which will be held at the Birmingham Medical Institute:
Mrs Denis Makepeace (Telephone: 0121 685 6574)

The Centre for Evidence-Based Mental Health at the University of Oxford's Department of Psychiatry would like to announce the Fourth Workshop on Evidence-Based Psychiatry, which will take place at Merton College, Oxford on 5-7 April 2000. This workshop will equip participants with the basic skills necessary to apply the principles of evidence-based medicine in psychiatry. The strategies covered will include searching for, and critically appraising evidence and using research findings in everyday clinical prac tice. The workshop will use a problembased approach, involving both smal group work and lectures, and will demonstrate how evidence-based medicine can help in making clinical decisions concerning diagnosis, treatment, prognosis and harm. There will also be plenty of opportunities for informal discussion. Applications can be made via Internet forms at: http://www.psychiatry.ox. ac.uk/cbmh/merton2000. Further information: Pat Gresham, Centre for Evidence-Based Mental Health, University Department of Psychiatry, Warneford Hospital, Oxford OX3 7JX (Telephone: 01865 226476; Fax: 01865 793101; Email: pat.gresham@pstch.ox.ac.uk).

The Politics of Recent Mental Health Policy is the title of a critical psychiatry day conference which will take place in central London on 7 April 2000. Some of the topics to be addressed include: community care without compulsion: incapacity and mental illness as a basis for psychiatric legislation; and compulsory community treatment: implications for patient rights and civil liberties. The conference will look into the history of mental health legislation in the 20th century and give the results of a recent survey of psychiatrists' opinions about community treatment orders and detention of people with personality disorder. There will also be workshops in the afternoon on advocacy, advance directives and challenging assumptions about drug treatment. Further information: Dr Joanna Moncrieff,
Charing Cross Department of Psychiatry (Telephone: 0181846 7336; E-mail: joannamoncrieff@compuserve.com) or Dr Jonathan Bindman, Institute of Psychiatry (E-mail: j.bindman@ iop.kcl.ac.uk)

The Belmont Postgraduate Psychiatric Centre would like to announce The 55th Residential Revision Course for the MRCPsych Examinations, which will take place at the University of Surrey, Guildford on 5-13 April 2000 (Part II) and 13-20 April 2000 (Part I). Further details: Mrs E. C. Denning, Belmont Postgraduate Psychiatric Centre, Chiltern Wing, Sutton Hospital, Sutton, Surrey SM2 5NF (Telephone: 0208296 4177).

The Association of Therapeutic Communities are the sponsors of Experiential Residential Workshop, an event which will be held in Kent on 5-7 May 2000. The course focuses on the use of intensive psychosocial treatment for borderline personality disorder and other clinical conditions and is designed for those who work in, or are interested in working in therapeutic communities. Further information: The Association of Therapeutic Communities, 13-15 Pine Street, London EC1R 0JH (Telephone/ fax: 0208950 9557; E-mail: post @ therapeuticcommunities.org).

The University of Manchester, Department of Psychiatry are the organisers of The 8th Manchester Course in Liaison Psychiatry, a week-long course which will take place on 5-9 June 2000. The course is most suitable for newly appointed consultants and specialist registrars. Emphasis is placed upon small group teaching and workshops. Clinical issues covered include somatisation, psychological reactions to physical illness and medico-legal aspects of liaison psychiatry. Other issues to be covered are managerial and administrative issues, research and audit. Further information: Mrs Una Dean, Secretary to Dr E. Guthrie, University Department of Psychiatry, Rawnsley Building, Manchester Royal Infirmary, Manchester M13 9WL (Telephone: 0161 276 5383; Fax: 0161273 2135; E-mail: Una.Dean@man.ac.uk). 